DOI: $10.12731 / 2658-6649-2020-12-5-42-52$

УДК 614.84

\title{
ЛЕСНЫЕ ПОЖАРЫ НА ТЕРРИТОРИИ ЕРМАКОВСКОГО МУНИЦИПАЛЬНОГО РАЙОНА КРАСНОЯРСКОГО КРАЯ В 2018 ГОДУ
}

\begin{abstract}
Коваль Ю.Н.
В статье приведен обзор пожаров, которые произошли на территории Ермаковского мунициипального района. Автор проанализировал особенности пожароопасного сезона в 2018 году, в частности - число пожаров, площуадь, освоенность лесной территории, климатические условия, растительность, а так же техническое оснащение и уровень охрань лесов. Рассмотренные лесные массивы распложены на особо охраняемых природных территориях, где обеспечивается активный отдых для населения. В связи, с чем высока вероятность пожаров от антропогенных факторов. Отмечено, что на начало пожароопасного сезона приходится самое большое количество пожаров - 89\%, которые происходят по вине человека. С апреля по июнь регистрируются 73\% пожаров, которые преобладают по площуади. А в июле высок риск пожара от «сухих» гроз. Однако, не смотря на сложность тушения пожаров и удаленность от населенных пунктов, отмечена слаженность и оперативность работь сотрудников лесопожарного иентра. Это подтверждается активной борьбой с лесными пожарами - 100\%.

Ключевые слова: анализ пожаров; пожароопасный период; лесные пожары; авиационное патрулирование; мониторинг.

\section{FOREST FIRE IN THE TERRITORY YERMAK MUNICIPAL AREA OF KRASNOYARSK REGION IN 2018}

\section{Koval Yu.N.}

The article provides an overview of the fires that occurred on the territory of the Ermakovsky municipal district. The author analyzed the features of the fire hazard season in 2018, in particular - the number of fires, area, forest de- 
velopment, climatic conditions, vegetation, as well as technical equipment and the level of forest protection. The considered forests are located in specially protected natural areas where active recreation is provided for the population. In this connection, the high probability of fires from anthropogenic factors. It is noted that at the beginning of the fire hazard season there is the largest number of fires $-89 \%$ that occur due to human faults. From April to June, $73 \%$ of fires are registered, which prevail in area. And in July, the risk of fire from "dry" thunderstorms is high. However, despite the complexity of extinguishing fires and the remoteness from settlements, the coherence and efficiency of the work of the employees of the forest fire center was noted. This is confirmed by an active fight against forest fires $-100 \%$.

Keywords: fire analysis; fire hazard; forest fires; air patrol; monitoring.

\section{Введение}

Ермаковский муниципальный район находится на территории Красноярского края в юго-восточной части. Территория на которой регистрируется наибольшее количество лесных пожаров - Усинское лесничество. На севере оно граничит с Ермаковским и Каратузским лесничеством; на юге и востоке - с Республикой Тыва; на западе - с Шушенским лесничеством и Саяно-Шушенским водохранилищем. Территория Усинского лесничества представлена единым лесным массивом, вытянутым с юго-запада на северо-восток. Общая площадь земель лесного фонда лесничества составляет 968314 гектаров, куда входят 893 квартала, при этом средняя величина лесного квартала составила 1084 га.

Породный состав преимущественно представлен хвойными породами с явным преобладанием лиственницы.

Особенность Усинского лесничества - наличие особо охраняемых природных территорий и объектов краевого значения, где обеспечивается активный отдых для населения:

- природный парк «Ергаки»;

- государственный комплексный заказник «Гагульская котловина»;

- памятник природы «Геологический разрез по реке Ореш»;

- охранная (буферная) зона государственного природного биосферного заповедника «Саяно-Шушенский».

В связи с наличием уникальных природных комплексов, являющихся привлекательным объектом туризма, увеличивается антропогенная нагрузка на территорию. Роль человека в возникновении и распространении лесных пожаров усиливается с каждым годом. Здесь практически 
нет участка леса, который в тот или иной период времени не испытывал антропогенного воздействия. В целях охраны и защиты территорий от лесных пожаров лесничество обслуживается Усинским авиационным отделением.

Усинское отделение Авиалесоохраны является структурным подразделением Ермаковского авиационного звена краевого государственного автономного учреждения «Лесопожарный центр», располагается на территории Усинского района Красноярского края. Функция «Леспопожарного центра» заключается в обеспечении пожарной безопасности района. Помимо основной деятельности сотрудники Авиалесоохраны ведут работу с молодежью и населением по противопожарной пропаганде в области охраны лесов.

Ежегодный объем мониторинга пожароопасной обстановки составляет 968,3 тыс. га, в том числе наземного - 145,6 тыс. га $(15,0 \%)$, и авиационного $-822,7$ тыс. га $(85,0 \%)$.

В целях своевременного обнаружения пожаров и их ликвидации предусмотрено противопожарное обустройство лесов в зонах наземной охраны в виде сети лесных дорог, в объеме 80 километров. В местах лесозаготовок, строительства различных объектов и трасс, зонах отдыха, по берегам водных объектов, среди лесных насаждений с высокой пожарной опасностью выделена зона авиационного патрулирования, которое осуществляется сотрудниками Усинского авиационного отделения КГАУ «Лесопожарный центр» Красноярского края.

Актуальность: Ежегодно лесные пожары охватывают площади от нескольких сотен до нескольких миллионов гектаров и оказывают разрушительное воздействие на окружающую среду. Достоверный прогноз лесопожарных рисков на пожароопасный период мог бы способствовать принятию оперативных мер по предупреждению лесных пожаров, повышению готовности сил и средств.

Цель: анализ случаев возникновения лесных пожаров на территории Ермаковского муниципального района Усинского авиационного отделения за 2018 год.

Задачи: 1. Провести анализ статистических данных лесных пожаров на территории Усинского авиационного отделения за 2018 год.

2. Изучить метеорологические показатели на территории Усинского авиационного отделения.

3. Изучить параметры лесных пожаров на территории Усинского авиационного отделения. 


\section{Материалы и методы исследования}

В базе данных о пожарах по материалам ФГУ «Авиалесоохрана», КГБУ «Усинское Лесничество», лесохозяйственному регламенту за 2018 год и спутниковым снимкам с сайтов NASA и ФАЛХ «Авиалесоохрана» размещены сведения о каждом лесном пожаре: расположение в квартальной сети лесничества, время обнаружения и ликвидации, причина возникновения, площадь пожара [1-5].

Подавляющее число лесных пожаров связывают с деятельностью человека, но необходимо учитывать различные факторы, способствующие возникновению и распространению пожаров. Главное значение играют погодные условия, поскольку от них напрямую зависит возможность возникновения лесных пожаров и ход дальнейшего развития.

Комплексный показатель пожарной опасности (КПО) лесных территорий рассчитывался с учетом влажности горючих материалов и особенностей суточных метеорологических данных [6]. Данный показатель рассчитывается по формуле:

где $\mathrm{n}$ - количество дней после дождя;

$$
\mathrm{K \Pi O}=\sum_{1}^{\mathrm{n}}|\mathrm{t}(\mathrm{t}-\mathrm{r})|
$$

$\mathrm{r}$ - точка росы для этой температуры воздуха, градусы;

$\mathrm{t}$ - температура воздуха на 13 ч.

Метеорологические данные были взяты с сайта rp5.ru. Анализировались показатели средней дневной и максимальной суточной температур, влажность воздуха и количество осадков как в день возникновения и прогрессирования пожара, так и за весь весенне-осенний период.

\section{Результаты исследования и их обсуждение}

Определение длительности пожароопасного сезона проводили с учетом освоенности территорий. Территория Усинского лесничества достаточно широко освоена человеком в хозяйственных целях и включает в себя орехово-промысловые зоны, участки лесов, имеющие научное, историческое, культурное и религиозное значение. Так как эксплуатационные леса занимают всего $26 \%$, то продолжительность пожароопасного сезона считали по датам установления - схода снежного покрова.

На основании освоенности лесов и нахождения на территории обширных территорий рекреационного значения можно сделать вывод, что в лесных массивах, широко освоенных человеком, доминируют антропогенные факторы возникновения пожаров. В малодоступных районах - природные источники, такие как «сухие грозы», которые распространены в июне. 
На территории Усинского авиационного отделения по данным лесохозяйственного регламента [2] длительность пожароопасного сезона составляет 175 дней. В целом по авиационному отделению средний класс пожарной опасности за последние три года равен 3,1 [7]. Это свидетельствует о возможности возникновения как низовых, так и верховых пожаров в пожароопасные периоды (весенне-летние и летне-осенние пожарные максимумы). Следует отметить, что за 2018 год ни одного верхового пожара на территории Усинского лесничества не произошло. Датой начала пожароопасного сезона в 2018 году следует считать 20 апреля.

Авиационное патрулирование территории согласно отчетам в 2018 году началось с 16 апреля и прекратилось в связи с отсутствием необходимости 23.09.2018. Помимо авиационного осмотра сотрудниками лесничества проводилось наземное патрулирование на автотранспорте. Начало наземного патрулирования - 08 апреля, завершение осмотров - 19.10.2018.

Патрулирование территории, охраняемой Усинским авиационным отделением, как авиационное, так и наземное проводилось согласно регламенту, в зависимости от класса пожарной опасности [8].

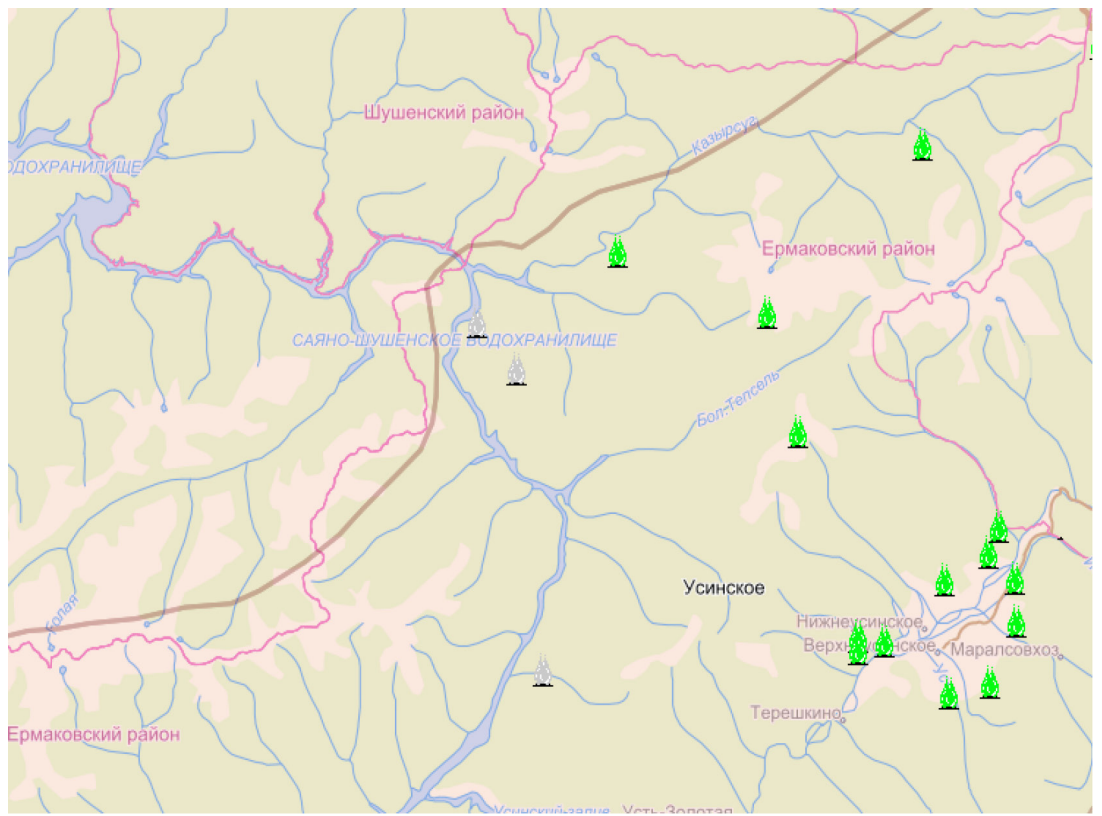

Рис. 1. Карта пожарной обстановки с апреля по сентябрь 2018 года 
На территории Усинского авиационного отделения в пожароопасный сезон регламент работы лесопожарных служб предусматривает определение суточного числа пожаров и определение классов пожарной опасности. Согласно статистическим данным за 2018 год на территории Усинского авиационного отделения за 209 дней в период с марта по сентябрь возникло 25 лесных пожаров, из которых семнадцать было зафиксировано авиацией. Наиболее часто возникали пожары в лесных массивах, относящиеся к III и к II классу пожарной опасности. По типу преобладали пожары низовые, беглые. Из них доля низовых слабых пожаров составила $60 \%$ от общего числа, низовых средних $-32 \%$, низовых сильных $-8 \%$. Это может быть связано с периодическими осадками, влажностью выше средних значений и не превышающей пиковые значения температуры в июле. Необходимо выделить вовремя проведенные противопожарные мероприятия, такие как создание минерализованных полос, уборка молодняка вдоль опушек с лесом, вырубка сухостойных деревьев.

Особенностью погодных условий пожароопасного сезона 2018 года можно отметить ранний сход снежного покрова весной и дефицит осадков в апреле, особо жаркий май и июнь с сухими грозами. В июле преобладала дождливая погода, в августе и сентябре были обильные осадки до самого окончания сезона. Все это отразилось на пожароопасной обстановке: ранние весенние пожары и грозовые пожары в начале лета [9].

Однако помимо благоприятных метеорологических условий и наличия горючего материала, для начала развития пожара необходим источник зажигания. По литературным данным только 3-5\% лесных пожаров происходят из-за располагающих природных факторов, таких как дефицит атмосферной и почвенной влаги, остальная часть лесных пожаров приходится на вину человека. В течение дня наиболее опасным является период $13 \div 18$ час, наименее опасным - $23 \div 8$ часов, когда возникло соответственно $59 \%$ и $2 \%$ всех пожаров. Анализ по дням недели показывает, что наибольшее количество пожаров возникает в субботу и воскресенье. Чаще всего возникновение лесных пожаров связывают с массовыми неконтролируемыми и не санкционированными весенними палами сухой травы на пограничных территориях и неосторожным обращением с огнем. На данный момент существует следующая проблема: многие сельскохозяйственные земли не используются по назначению, выходят из оборота, вследствие чего зарастают травой. Из-за попадания в такие места источника зажигания происходят большие выгорания травы. В результате огонь распространяется огромной полосой на несколько десятков километров 
по нелесному фронту, а затем может изменить направление из-за ветра и распространиться в лесные массивы [10].

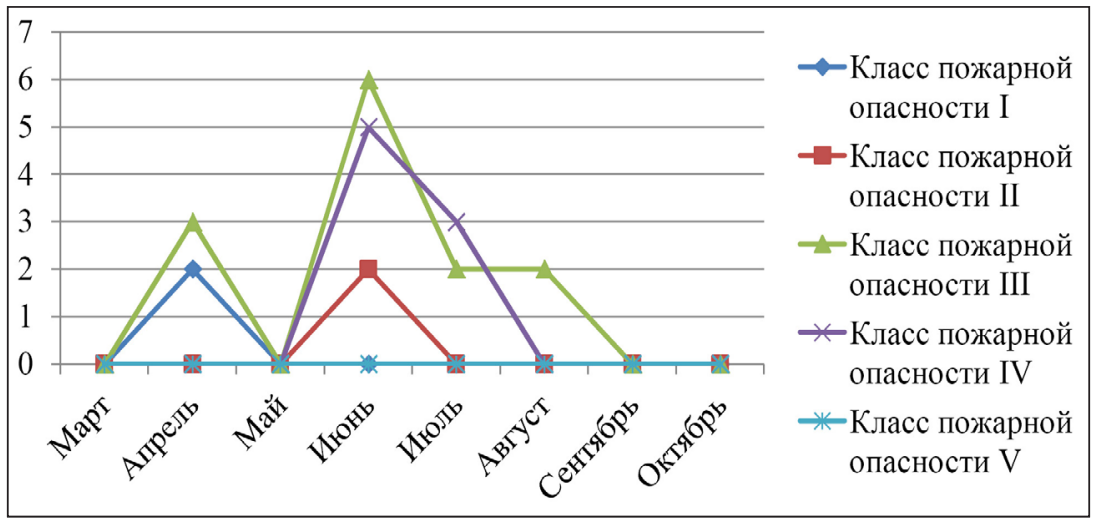

Рис. 2. Динамика обнаруженных лесных пожаров авиацией

Всего за пожароопасный сезон на территории, охраняемой Усинским авиационным отделением, возникло 25 лесных пожаров. Из них: 13 пожаров в авиационной зоне, (в т.ч. 3-в зоне контроля), и 12 в наземной зоне. Авиацией обнаружено 17 лесных пожаров, что составляет, 68 \% от общего числа пожаров. Наиболее значительные повреждения лесного массива выявлены на площади 5 гектар, при низовом беглом пожаре, произошедшем в мае.

Для того чтобы оценить корреляцию между пожароопасным состоянием лесов и ежемесячными изменениями метрологических условий анализировались показатели по количеству пожаров и площади лесных земель, пройденных пожарами. Так, больший модуль корреляционного значения $(0,95)$ отмечен в апреле и мае, в августе и сентябре его величина составила 0,84 , что так же указывает на явную взаимосвязь между метрологическими условиями и количеством пожаров.

Полученные результаты свидетельствуют о наличии зависимости между степенью поражения лесных пожаров и погодными условиями. В 2018 году отмечен аномально жаркий май с крайне высокой суточной температурой, влажностью воздуха ниже $50 \%$, низким количеством осадков до июля месяца, что способствовало развитию и прогрессированию лесных пожаров. В тех месяцах (август и сентябрь), когда количество осадков превышало средние объемы, пожары в лесных массивах имели значительно меньшую площадь поражения и быстро ликвидировались [11]. 
В тушении всех пожаров участвовали работники Усинского авиационного отделения и сотрудники лесничества. Авиационная техника производила мониторинг пожарной обстановки с воздуха, и в случае фиксации помогала притушить основное пламя. Для полной ликвидации лесных пожаров спасатели и лесники направлялись наземным транспортом. В целом можно отметить, что личный состав авиационного отделения в течение всего пожароопасного сезона работал слаженно и оперативно, процент активной борьбы - 100\% [12].

\section{Выводы}

Данные проведенного исследования показывают наличие корреляции между метеорологическими показателями и характеристикой пожаров на территории Усинского авиационного отделения. При проведении и разработке противопожарных мер необходимо уделить внимание суточной температуре и количеству осадков, так как крайние значения этих показателей создают благоприятные условия для возникновения лесных пожаров. Также необходимо отметить мероприятия по противопожарной пропаганде всех слоев населения. Это позволит свести к минимуму ущерб, наносимый лесными пожарами $[13,14]$.

Согласно произведённому анализу и показателей за прошлые годы, можно сделать вывод, что в ближайшие годы ожидает рост количества лесных пожаров. Уже сейчас положение с лесными пожарами в ряде регионов России стало катастрофическим. Это означает, что охранные мероприятия по защите лесов должны быть направлены как на борьбу с пожарами, в том числе с их ранним обнаружением, так и на сокращение главной первопричины лесных пожаров - человеческого фактора.

Автор выражает отдельную благодарность А.Г. Акуловулетчику-наблюдателю Усинского авиаиионного отделения ФГУ «Авиалесоохрана».

\section{Список литературы}

1. ФГУ «Авиалесоохрана»: [сайт]. URL: http:// www.aviales.ru/ (дата обращения: 01.10.2019).

2. Лесохозяйственный регламент [Электронный ресурc]. URL: http://docs. cntd.ru/document/550203483 (дата обращения: 01.10.2019).

3. Территориальный орган Федеральной службы государственной статистики по Красноярскому краю [Электронный ресурc]. URL: http://www.krasstat. gks.ru (дата обращения: 01.10.2019). 
4. Федеральное агентство лесного хозяйства [Электронный ресурс]. URL: http://www.aviales.ru (дата обращения: 01.10.2019).

5. NASA: [сайт]. URL: http://rapidfi re.sci.gsfc.nasa.gov (дата обращения: 01.10.2019).

6. Глаголев В.А., Коган Р.М. Шкала классов пожарной опасности по метеоусловиям климата средних широт // Лесное хозяйство. 2012. № 1. С. 44-46.

7. Кац А.Л., Гусев В.Л., Шабунина Т.А. Методические указания по прогнозированию пожарной опасности в лесах по условиям погоды. М.: Гидрометеоиздат, 1975. $16 \mathrm{c.}$

8. Курбатский Н.П. Пожарная опасность в лесу и ее измерение по местным шкалам // Лесные пожары и борьба с ними. М.: Изд-воАНСССР, 1963. С. 5-30.

9. Коровин Г.Н., Зукерт Н.В. Влияние климатических изменений на лесные пожары в России // Климатические изменения: взгляд из России / под ред. В.И. Данилова-Данильяна. М.: ТЕИС, 2003. С. 69-98.

10. Санников С.Н. Лесные пожары как фактор преобразования структуры, возобновления и эволюции биогеоценоза // Экология. 1981. N 6. С. 23-33.

11. Харин В.В., Бобринев Е.В., Удавцова Е.Ю., Кондашов А.А. Сравнительный анализ показателей оперативного реагирования подразделений различных видов пожарной охраны // Сибирский пожарно-спасательный вестник. 2019. № 2 (13). С. 54-58.

12. Долгушина Л.В., Мельник А.А., Батуро А.Н., Иванов Д.В. Основные причины и перспективные направления профилактики природных пожаров на примере Красноярского края // Сибирский пожарно-спасательный вестник. 2017. № 4 (7). C. 9-14.

13. Пожаркова И.Н., Гапоненко М.В., Полосухина Д.А., Рублева М.Е. Мониторинг восстановления лесных сообществ после воздействия пожаров на территории Юксеевского лесничества // Сибирский пожарно-спасательный вестник. 2017. № 1 (4). С. 17-21.

14. Зяблицкий А.М., Ефремов И.Г., Лагунов А.Н., Пожаркова И.Н. Автоматизация решения задач мониторинга и прогнозирования ЧС // Мониторинг, моделирование и прогнозирование опасных природных явлений и чрезвычайных ситуаций : Сборник статей по материалам VIII Всероссийской научно-практической конференции. 2018. С. 110-113.

\section{References}

1. Avialesokhrana. http://www.aviales.ru/

2. Forestry regulations. http://docs.cntd.ru/document/550203483

3. Territorial body of the Federal State Statistics Service for the Krasnoyarsk Territory. http://www.krasstat.gks.ru 
4. Federal agency of forestry. http://www.aviales.ru

5. NASA. http://rapidfi re.sci.gsfc.nasa.gov

6. Glagolev V.A., Kogan R.M. Shkala klassov pozharnoy opasnosti po meteousloviyam klimata srednikh shirot [Scale of fire hazard classes on the meteorological conditions of the climate of middle latitudes]. Lesnoe khozyaystvo [Forestry]. 2012. N. 1, pp. 44-46.

7. Katz A.L., Gusev V.L., Shabunina T.A. Metodicheskie ukazaniya po prognozirovaniyu pozharnoy opasnosti v lesakh po usloviyam pogody [Methodical instructions for forecasting fire hazard in forests based on weather conditions]. Moscow: Gidrometeoizdat, 1975.16 p.

8. Kurbatsky N.P. Pozharnaya opasnost'v lesu i ee izmerenie po mestnym shkalam [Fire hazard in the forest and its measurement on local scales]. Lesnye pozhary $i$ bor'ba s nimi [Forest fires and fight against them]. M.: Publishing house of ANSSSR, 1963, pp. 5-30.

9. Korovin G.N., Zukert N.V. Vliyanie klimaticheskikh izmeneniy na lesnye pozhary $\mathrm{v}$ Rossii [The impact of climatic changes on forest fires in Russia]. Klimaticheskie izmeneniya: vzglyad iz Rossii [Climatic changes: a view from Russia] / ed. V.I. Danilov-Danilyan. M.: TEIS, 2003, pp. 69-98.

10. Sannikov S.N. Lesnye pozhary kak faktor preobrazovaniya struktury, vozobnovleniya i evolyutsii biogeotsenoza [Forest fires as a factor of structure transformation, renewal and evolution of biogeocenosis]. Ekologiya [Ecology]. 1981. N. 6, pp. 23-33.

11. Kharin V.V., Bobrinev E.V., Udavtsova E.Yu., Kondashov A.A. Sravnitel'nyy analiz pokazateley operativnogo reagirovaniya podrazdeleniy razlichnykh vidov pozharnoy okhrany [Comparative analysis of indicators of operational response of units of different types of fire protection]. Sibirskiy pozharno-spasatel'nyy vestnik [Siberian Fire and Rescue Bulletin]. 2019. N 2 (13), pp. 54-58.

12. Dolgushina L.V., Melnik A.A., Baturo A.N., Ivanov D.V. Osnovnye prichiny i perspektivnye napravleniya profilaktiki prirodnykh pozharov na primere Krasnoyarskogo kraya [The main reasons and promising directions for the prevention of wildfires on the example of the Krasnoyarsk Territory]. Sibirskiy pozharno-spasatel'nyy vestnik [Siberian Fire and Rescue Bulletin]. 2017. N 4 (7), pp. 9-14.

13. Pozharkova I.N., Gaponenko M.V., Polosukhina D.A., Rubleva M.E. Monitoring vosstanovleniya lesnykh soobshchestv posle vozdeystviya pozharov na territorii Yukseevskogo lesnichestva [Monitoring of the restoration of forest communities after the impact of fires on the territory of the Yukseevskoe forestry]. Sibirskiy pozharno-spasatel'nyy vestnik [Siberian fire and rescue bulletin]. 2017. N 1 (4), pp. 17-21. 
14. Zyablitsky A.M., Efremov I.G., Lagunov A.N., Pozharkova I.N. Avtomatizatsiya resheniya zadach monitoringa i prognozirovaniya ChS [Automation of solving problems of monitoring and forecasting emergency situations]. Monitoring, modelirovanie i prognozirovanie opasnykh prirodnykh yavleniy i chrezvychaynykh situatsiy : Sbornik statey po materialam VIII Vserossiyskoy nauchno-prakticheskoy konferentsii [Monitoring, modeling and forecasting of natural hazards and emergency situations: Collection of articles based on the materials of the VIII All-Russian scientific and practical conference]. 2018, pp. 110-113.

\section{ДАННЫЕ ОБ АВТОРЕ}

Коваль Юлия Николаевна, доцент, канд. биол. наук

ФГБОУ ВО Сибирская пожарно-спасательная академия ГПС МЧС России

ул. Северная, 1, г. Железногорск, 662972, Красноярский край, Российская Федерация

a_yulya@inbox.ru

\section{DATA ABOUT THE AUTHOR}

Koval Yulia Nikolaevna, Associate Professor, Ph.D.

Siberian Fire and Rescue Academy of the State Fire Service of the Ministry of Emergencies of Russia

1, Severnaya Str., Zheleznogorsk, 662972, Krasnoyarsk Region, Russian Federation

a_yulya@inbox.ru

ORCID: 0000-0001-5482-6439 